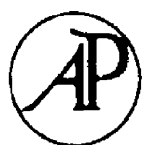

ELSEVIER

\title{
HCI and MIS: shared concerns
}

\author{
Ping Zhang ${ }^{\mathrm{a}}$, Andrew Dillon ${ }^{\mathrm{b}}$ \\ ${ }^{a}$ School of Information Studies, Syracuse University, Syracuse, New York, NY 13244-4100, USA \\ ${ }^{\mathrm{b}}$ School of Information, The University of Texas at Austin, Austin, TX 78712, USA
}

Received 15 November 2002; received in revised form 24 February 2003; accepted 31 March 2003

\begin{abstract}
The fields of HCI and MIS share many concerns but have traditionally not shared literatures, theories and results. This special issue is a first attempt at bridging the disciplinary divide. In this paper, the history of both fields is briefly outlined and reasons for the independence of each are examined. The criteria for paper inclusion are outlined and each paper is briefly introduced.
\end{abstract}

(C) 2003 Elsevier Ltd. All rights reserved.

Keywords: Human-Computer Interaction; Management Information Systems; Website design; User acceptance of technology; E-service adoption; Flow

\section{Motivation of the special issue}

In an age of disciplinary shift and calls for greater cross-disciplinary interaction among various disciplines, it is timely to consider how related are those research areas that take the human use of computers as their basic area of concern. It is clear that research into the human response to technology has taken many forms and been given many names over the last few decades: human factors, information design, human-computer interaction (HCI), ergonomics, management information systems (MIS), information management, computer-supported collaborative work, etc. Unfortunately, it is also too apparent from the literature on these topics that many of the key researchers and thinkers in these areas have tended to address audiences who identify with one rather than all of these areas. It may be that the issues involved are too wide for any one field to cover but it is also true that the exchange of ideas and the sharing of theoretical insights have been vexingly limited. Specifically, two

E-mail addresses: pzhang@syr.edu (P. Zhang), adillon@ischool.utexas.edu (A. Dillon). 
largely independent literatures on humans and technology have emerged since the 1970s: HCI and MIS. Both have their own conferences, journals, professional societies and research agenda yet both have research agenda focused on very similar problems. This special issue of IJHCS is the result of an attempt to bring these two fields of practice closer together. It is the first of a continuous effort of the Special Interest Group on HCI of the Association for Information Systems (AIS SIGHCI) to disseminate research results on human aspects in MIS to other related fields.

The field of HCI has always considered the design of usable information technology to be its own concern. Since the first paper on the ergonomics of a computer (Shackel, 1959) to the emergence of regular conferences on interface design and interaction, the field has attracted numerous scholars focused on usability, user experiences, task design, and the evaluation of performance in interactive systems. HCI places strong emphasis on understanding how users can perform certain tasks in given work contexts and on using such understandings to inform the design of technology that is both useful and usable. From the outset, HCI attracted psychologists to the field to shed light on user cognition, and since then the field has opened its doors to anthropologists and organizational specialists to help shed light on the dynamics of group behavior and cognition "in the wild" (Hutchins, 1995) as well as to learning theorists to inform the analysis of HCI in educational contexts (Nilsson and Mayer, 2002).

Independently, the MIS field has tackled similar issues but often with a slightly different emphasis. As a community of scholars interested in the development, use, and impact of information technology and systems in broadly defined social and organizational settings, MIS has been through a steady shift from what was a techno-centric focus to a better balanced technology/organizational/management/ social focus (Baskerville and Myers, 2002). User attitude, perceptions, acceptance and use of IT have been long standing issues and major themes of MIS since early days in computing (Swanson, 1974; Lucas, 1975). Also extensively studied are IS development theories and methodologies, collaborative work and computermediated communication, representations of information for supporting managerial tasks, and computer training. All these studies have grown significantly during the last three decades with the maturity of theoretical frameworks and models. Such work has advanced our understanding of human factors in a significant manner.

To date however, the HCI and MIS fields have largely evolved independently with only minimum influence on each other. Leading researchers in one field tend not to publish in the journals and conference proceedings of the other field. Citation patterns among authors reveal limited cross-pollination of literatures with the result that students of either field are often under-exposed to ideas and findings that are relevant to their research. It is likely that scholars for each field who are prepared to cross-boundaries will experience the surprise once felt by both editors of sitting in a session at a conference for the "other" field and feeling simultaneously comfortable and uncomfortable with what one hears. How can it be, we have both thought, that so much relevant work is missed or unattended to in "my" field?

In part it seems likely that this independence may have evolved from the academic homes of the respective fields. MIS has traditionally been the province of Business 
Schools (even though a large portion of MIS programs and scholars are outside such schools), while HCI has tended to be located in Computer Science and/or Psychology programs. While there are exceptions and indeed recent evidence of standalone HCI schools and departments along with new schools of Information, Informatics, and Information Studies, the norm has been for ready-made disciplinary divides to result from the location of academic silos in 20th century universities, silos that one must surely question in the information age. True, there are issues that either field has largely taken on independently, e.g. HCI has made the user-centered design process its own area of concern, while MIS has taken the lead in understanding resistance to new technology in the work and marketplace. However, the differences and exceptions are far fewer than the shared concerns, and it seems more than short sighted not to build on these.

Both HCI and MIS are interdisciplinary and applied fields. They share some common reference disciplines such as cognitive psychology, social psychology, computer science, communication, and many others. They also share many common research methodologies. Most importantly, the two fields share common research issues and problems with many of these issues emerging over the recent years (Zhang et al., 2002). In a nutshell we might summarize the shared research goal as being the increased theoretical and practical understanding of how information technology can best be designed and implemented to suit user and organizational needs. That much is easy to say. However underneath this general goal there exist many possible research and practice strategies that can be followed.

In considering papers for this special issue, we wanted to emphasize not merely quality work but a clear articulation from all contributors of the shared goals of MIS and HCI and how their work could be placed within a broader perspective of studies into human aspects of information technology. The papers included in this special issue do not cover all possible research streams or sub areas. Such breadth is beyond any one special issue of a journal. But rather, they are a starting point to consciously bring the two fields closer to each other and to influence research and collaborations among scholars in both fields.

\section{Some background and the paper selection process}

AIS SIGHCI is one of the first six SIGs approved by AIS Council and publicized in ISWORLD in July 2001. Ping Zhang and Fiona Nah founded it with the purpose of recognizing, encouraging and promoting research studies on the human aspects of IS/IT research within the MIS community. AIS SIGHCI provides a forum and networking opportunities for scholars to acknowledge each other's work, to discuss issues related to the history, theories, practice, methodologies and techniques, new development, and applications of the interaction between humans, tasks, information technologies, and contexts. Its mission is two-fold: (1) To facilitate the exchange, development, communication, and dissemination of information among AIS members, and, (2) To promote research related to HCI within business, 
managerial, and organizational contexts among AIS members and to the larger community of practitioners and scholars.

AIS SIGHCI provides a range of services to its members in support of its mission (more details can be found at http://melody.syr.edu/hci). Most noticeable are the SIGHCI sponsored get-togethers at the two major MIS conferences. SIGHCI organizes regular HCI minitracks at Americas Conference on Information Systems (AMCIS) and research workshops prior to the International Conference on Information Systems (ICIS).

The papers in this special issue are expansions of the best papers from the HCI Studies in MIS minitrack at the 8th Americas Conference on Information Systems, held in Dallas, TX August 2002. This minitrack is the first one organized by SIGHCI. It attracted 27 submissions, among which 18 were accepted for presentation at the conference. Eleven of the 18 articles were in high quality and thus were invited for expansion and possible inclusion in the IJHCS special issue. Authors of ten papers responded. Each of the 10 expansions went through a rigorous review process with three reviewers. Based on the review results and guest editors' evaluation, six papers were conditionally accepted. After another round of revisions and guest editors' evaluation, five were finally accepted for this special issue.

\section{Introduction to the papers}

The papers included in this issue reflect a concern with issues that transcend narrow disciplinary divides yet, at the same time, are informed by and themselves inform, the traditional approaches of MIS and HCI.

Since the inception of the web in the early 1990s, website and webpage design has been a topic of interest to designers, organizations, marketers, and researchers in many fields owing to the continued and ever growing influence web design has on users and organizations. Ryan, Field, Olfman, in their paper "The Evolution of US State Government Home Pages from 1997 to 2002," seek to discover the dimensions underlying people's perceptions of state government home pages, to observe how those dimensions have changed over the years, to identify different types of state home pages, and to see how these types have changed. Based on empirical data, the authors develop a taxonomy of four state government home page types based on three perceptual dimensions: layout, navigation support, and information density. Although the study is situated with state government homepages, the taxonomy and perception dimensions of web homepages almost certainly have implications to other contexts and influence designers of future web homepages.

The analysis and modeling of user acceptance of technology has a long history within MIS and has recently become a topic of interest for HCI folks who are seeing the limitations of usability alone. In this issue, two papers address acceptance in the broad sense and indicate how the process remains a complex problem for theorists in both disciplines.

$\mathrm{Yi}$ and Hwang's paper, "Predicting the Use of Web-Based Information Systems: Self-efficacy, Enjoyment, Learning Goal Orientation, and the Technology 
Acceptance Model" examines and confirms the importance of motivation (selfefficacy), learning goal orientation, and enjoyment on students' actual use of a webbased class management system. By investigating these new variables, the study extends the technology acceptance model and contributes to the large literature of technology acceptance studies.

With the fast growth of Internet based organizations, Internet-delivered e-services become an important area for business opportunities and research studies. In "Predicting E-Services Adoption: A Perceived Risk Facets Perspective," Featherman and Pavlou study how consumers evaluate e-services for potential adoption. Unlike studies on technology acceptance that primarily focus on positive utility, this research investigates the impact of negative utility on e-services adoption. Results indicate that e-services adoption is adversely affected primarily by performancebased risk perceptions, and perceived ease of use of the e-service reduced these risk concerns.

Tapping on the intrinsic motivation of individuals interacting with technologies, flow theory has been applied in the computer-mediated environments by researchers in several fields, including HCI, MIS, and communication. Existing studies have shown that experience of flow leads to increased exploratory behavior, communication, learning, positive affect, satisfaction and acceptance of technology, and computer use. However, the precise nature of flow in interaction design has yet to be fully articulated. In "A Person-Artifact-Task (PAT) Model of Flow Antecedents in Computer-Mediated Environments," Finneran and Zhang first identify the ambiguities and inconsistency problems in the conceptualization and application of the flow theory in existing studies. Then they propose a parsimonious model to synthesize and project the important factors that contribute to a flow experience in HCI.

If we are to truly bridge disciplinary divides, there needs to be more than dialog and shared publications. The fields of MIS and HCI must share curricula and engage in educational activities that mix concepts, models and theories from both communities. With this in mind, we are pleased to include the last paper in this set, "Issues and Strategies for Integrating HCI in Masters Level MIS and ECommerce Programs" by Chan, Wolfe, and Fan. The authors discuss issues and approaches for integrating HCI topics into masters level MIS/EC programs. A case study illustrates how HCI topics can be taught as a stand-alone course or incorporated in existing MIS/EC courses. Drawing from the case study, the paper also addresses pedagogical challenges regarding student skill sets, learning outcomes, innovative pedagogies, tools and technology, and HCI issues for advanced IS/EC topics.

\section{Acknowledgements}

We want to thank authors who made great contribution to the special issue and the important effort of bridging the two fields. We also want to express our sincere appreciation to the 18 reviewers who played a vital role in the process. These 
reviewers are: Guru Ashu, Susy Chan, Subhasish Dasgupta, Xiaowen Fang, Mauricio Featherman, Richard Field, Jane Gravill, Jeff Hsu, Yujong Hwang, Xiao Li, Shin-jeng Lin, Nancy Lightner, Barbara Marcolin, Lorne Olfman, Terry Ryan, Rosalee Wolfe, Mun Yin, and Wenli Zhu.

The editors would also like to acknowledge the support of Brian Gaines, IJHCS editor-in-chief, in bringing the idea for a special issue on this topic to fruition.

\section{References}

Baskerville, R.L., Myers, M.D., 2002. Information systems as a reference discipline. MIS Quarterly 26 (1), $1-14$.

Hutchins, E., 1995. Cognition in the Wild. MIT Press, Cambridge, MA.

Lucas, H.C., 1975. Performance and the use of an information system. Management Science 21 (8), 908-919.

Nilsson, R., Mayer, R., 2002. The effects of graphic organizers giving cues to the structure of a hypertext document on users' navigation strategies and performance. International Journal of HumanComputer Studies 57 (1), 1-26.

Shackel, B., 1959. Ergonomics for a computer. Design 120, 36-39.

Swanson, E.B., 1974. Management information systems: appreciation and involvement. Management Science 21 (2), 178-188.

Zhang, P., Benbasat, I., Carey, J., Davis, F., Galletta, D., Strong, D., 2002. Human-computer interaction research in the MIS discipline. Communications of the AIS 9 (20), 334-355. 